\title{
A Multiobjective SDSS for Management of Urbanizing Watersheds: The Case of the Lower Kaskaskia Basin, Illinois
}

\author{
Kyle O. Allred \\ John W. Nicklow \\ Misgana K. Muleta \\ Leslie A. Duram
}

\begin{abstract}
The conversion of natural and agriculturally dominated watersheds to industrial, commercial and residential developments leads to a cascade of adjustments in runoff quantity and stream quality at locations further downstream. The use of sophisticated hydrologic simulation models and Geographic Information Systems (GIS) has become the standard for evaluating these impacts of urban sprawl on water resources systems. Simulation and GIS models alone, however, are incapable of directly revealing optimal land development patterns that meet specified objectives. This paper describes the development of a multi-objective Spatial Decision Support System (SDSS) designed to overcome this limitation. The SDSS is created by integrating the U.S. Department of Agriculture's Soil and Water Assessment Tool (SWAT) for comprehensive hydrologic simulation, a GIS for generating input and visualizing output, and a genetic algorithm (GA) for identifying weighted, optimal land use patterns. In addition to the GA, future research will involve the integration of a second search mechanism, the artificial life algorithm, to verify optimal results. The optimal landscape is that which minimizes sediment yield in subsequent streams, while simultaneously maximizing approximate anticipated profit from urban development. The SDSS could be a useful visualization tool for land use managers and watershed management institutions in planning new developments. The SDSS has been tested on the Lower Kaskaskia watershed, located in the Metro East area of southwestern Illinois. Evidenced by a historical survey of population growth and hydrologic and water quality variability, this basin is an example of a watershed that is undergoing extensive water resources changes as a result of urbanization. An investigation of watershed planning activities and stakeholder groups in the watershed has also been undertaken. Meetings with these individuals have allowed direct dissemination of the research to affected groups and have been useful for generating feedback on future work and model modifications.
\end{abstract}

\section{Introduction and Background}

As increasing urban development become ever more apparent, the need to understand and control the environmental effects of urban sprawl intensifies. As a result, decision makers involved in land management are in need of specialized tools for evaluating optimal land 
development strategies. For example, a typical problem facing decision makers is the evaluation of land use patterns that

Minimize $\rightarrow$ The adverse effects on water quality and quantity caused by urbanization, and; $(-1) \times$ economic growth and profit to be earned through urbanization.

Subject To $\rightarrow$ (i) Physical, chemical and biological laws governing watershed hydrology and ecology; and

(ii) Realistic bound constraints on the feasible land development.

Since its introduction in the early 1960's, Geographic Information Systems (GIS) have been increasingly popular for studying a variety of similar spatial problems (DeMers, 2000). A GIS is designed to store, retrieve, manipulate, analyze, and display spatial data. The disadvantage to using GIS in this manner is that, alone, it does not have the capability to perform complex process modeling. In order to overcome this limitation, many modeling systems have evolved and coupled GIS with process (i.e., environmental or hydrologic) simulation models to work together as one integrated system. Because GIS has the ability to handle both temporal and attribute data, it has the capability to increase the accuracy and quality of simulation modeling. Moreover, the principle goal in most modeling is to be able to handle large amounts of geographic data, a task which can be performed easily by GIS (Nyerges, 1993). A GIS that easily integrates models has been called a "Geographic Information Modeling System" (Dangermond, 1987). The subsystems of a coupled system include input/capture, management, manipulation/analysis, and output/display.

The words loose and tight have been used to describe coupled environments and refer to the compatibility of data constructs of the subsystems with the software operations used to process them (Nyerges, 1993). A loosely coupled system is a system in which a simple data transfer takes place from one system to another. An example of a loosely coupled system is joining, or coupling, two separate GIS modules in order to transfer data between the two. A GIS and model are said to be tightly coupled when they rely on an integrated data management system. The tightest coupling is called an embedded system where both the GIS and the hydrologic model rely on the same data source. As can be expected, this is very complicated, and due to the complexity of an embedded system, they are financially and computationally expensive to develop. Furthermore, the user is often left with a system that is very case specific and is most likely incompatible to problems of different disciplines. For this reason looser, more generic, systems are much more common.

Although coupled GIS/hydrologic modeling systems greatly improve capabilities for analyzing spatial problems, including the evaluation of environmental effects of urban sprawl, they are incapable of directly determining optimal land development strategies. In essence, their results begin to lose importance when viewed in light of objectives, sometimes multiple in number and conflicting in nature, to be achieved. As a result, researchers are increasingly making use of integrated software systems called Decision Support Systems (DSS) and Spatial Decision Support Systems (SDSS). A DSS acts as a framework for operations research and data management systems (Sprague, 1980). An SDSS further integrates database management 
systems with analytical models (i.e., hydrologic models), graphical display (i.e., map layouts) and tabular reporting capabilities (i.e., ASCII files, spreadsheets), and the expert knowledge of the decision maker (i.e. land use manager) (Densham, 1991).

Multi-criteria evaluation (MCE) techniques, also referred to as multi-criteria analysis or MCA, can be integrated within an SDSS to analyze the complex trade-offs between quantitative choice alternatives with different socio-economic impacts. The primary objective of MCE techniques is to investigate a number of possibilities in the light of multiple criteria and conflicting objectives (Voogd, 1983; Carver, 1991). A particular class of methods that are well suited for an SDSS is the multiple criteria decision-making (MCDM) method, in which MCE techniques are a component. The general objective of MCDM is to help the decision maker select the best alternative based on a number of possible alternatives in the presence of multiple-choice criteria (Jankowski, 1995). Another important aspect of an SDSS is the operations research, or optimization, component. Here, the purpose of the optimization is to reveal better decisions by starting with an initial concept and using information gained through previous iterations to improve upon the idea. A genetic algorithm (GA), although heuristic in nature, could be used in this sense. GAs follow the principles of Darwinian natural selection, where only the strong individuals survive. Starting with an initial population, the chromosomes (i.e., alternative decisions) evolve through a series of operations, including ranking according to fitness, mating, crossover, and mutation (Haupt and Haupt, 1998).

For this project, a tightly coupled model and a GA are integrated within an SDSS. The resulting modeling system has been applied to the Lower Kaskaskia watershed that is located in southwest Illinois, near St. Louis, in an area called Metro East. The goal of the model is to identify land use patterns that minimize sediment yield, while maximizing the approximate anticipated economic profit to be earned from urbanization.

\section{Evaluation of Urban Sprawl and Its Effects}

An attempt was first made to conduct a historical population survey for the watershed to determine the extent of urban sprawl near the Metro East area in recent years. This survey was completed using population census data from the U.S. Census Bureau and was conducted on a census tract scale. When originally delineated, census tracts were homogeneous with respect to population characteristics, economic status, and living conditions. They are maintained with the intent of making comparisons between subsequent census surveys. Some tracts in densley populated areas required subdivision due to the increase of population in the area (USCB, 2000). A GIS overlay technique was used to determine which census tracts fell within the Lower Kaskaskia watershed, and data was subsequently collected for each tract. The data from the 2000 census was very thorough, but the availabiltiy of data decreased for each preceding census, and census tract data was only available from 1970 to 2000. In addition, the comparison of the 2000 census and 1990 census proved to be difficult due to the fact that some census tracts were redelineated in 2000. Finally, the source for 1970 and 1980 data did not include some data for rural areas. Based on available data, the census tracts were compared using the percent change in total population that occurred within the corresponding decade. The results of the survey, 
illustrated in Figure 1, generally indicate an increase in population, particularly in areas that serve as subburban or bedroom communities to St. Louis. In addition to the population survey, a separate review of historical changes in peak flow and water quality at various stream locations has confirmed a general increase in runoff quantity and sediment loads in the watershed.
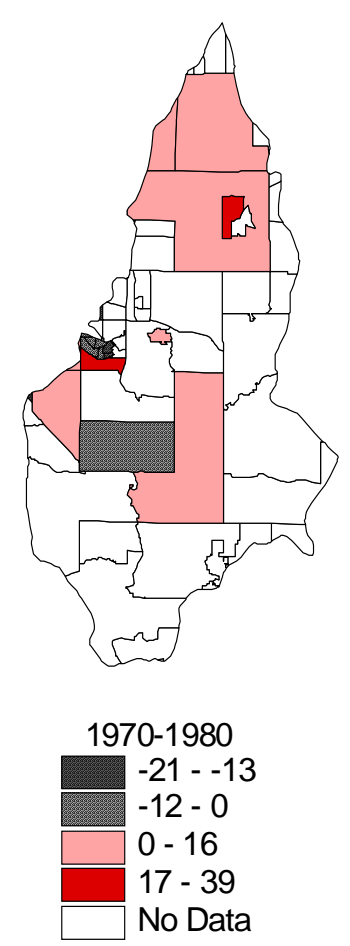
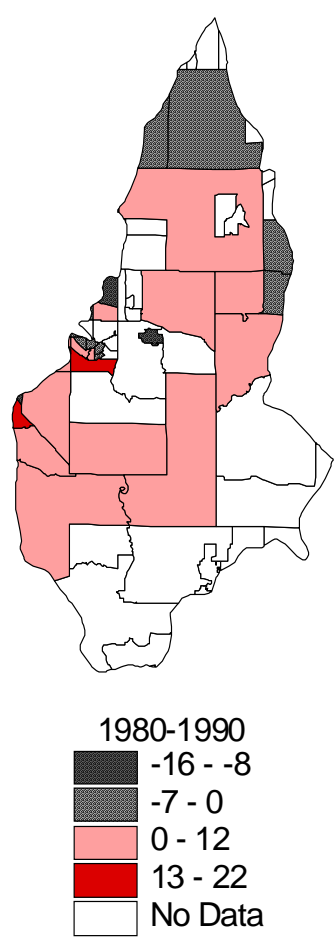
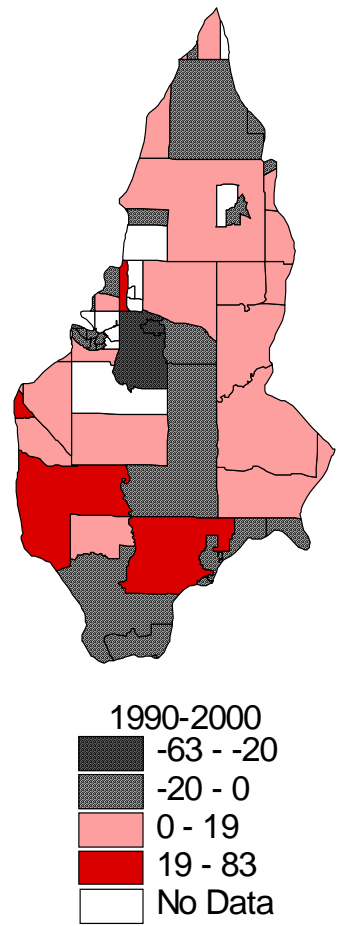

Figure 1. Historical Population Trends

\section{Hydrologic Simulation Model - SWAT}

The hydrologic model used within the SDSS is the U.S. Department of Agriculture's Soil and Water Assessment Tool (SWAT) (Arnold et al, 1998). SWAT is a widely accepted, comprehensive, distributed, watershed-scale model that runs on an ArcView GIS platform, making it a tightly coupled system. The model was designed to predict the impact of land management practices on agricultural chemicals, sediment and water. In simulating hydrologic processes, it considers topography (DEM), land use, soil type, vegetation, and weather conditions such as climate and precipitation. In addition, physical processes associated with water transport, such as sediment flow, nutrient cycling, and crop growth, can all be modeled directly from SWAT.

Some of the benefits of SWAT are that it subdivides the watershed into smaller subbasins to accommodate differing soil types, land uses, weather, and topography. It can handle large watersheds, up to thousands of square miles, uses readily available GIS inputs, and is 
computationally efficient for single simulation runs (Arnold et al, 1998). The latest version of SWAT (i.e., SWAT2000) has become part of the U.S. Environmental Protection Agency's BASINS toolkit for watershed simulation (USDA, 2000).

SWAT uses the Modified Universal Soil Loss Equation (MUSLE) to predict the amount of erosion based on rainfall pattern, soil type, topography, crop system and management practices. The MUSLE can be written as

$$
A=90.5(Q q)^{0.56} K C P(L S)
$$

where $A$ represents the potential long-term average annual soil loss in tons per acre per year; $Q$ is the surface discharge; $q$ is the peak rate of runoff; $K$ is the soil erodibility factor, which indicates the susceptibility of soil particles to detachment from runoff; $L S$ is the slope length-gradient factor; $C$ is the crop/vegetation and management factor, determined from crop types, tillage methods, residue treatments, and other agricultural practices; and $P$ is the support practice factor, which accounts for practices such as strip cropping, contour farming and terracing that can reduce the soil transporting capacity of runoff. (IWMC, 2003).

\section{Solution Methodology and Example Application}

In application of the SDSS, the GA is used to specify various land use patterns corresponding to levels of urbanization. As shown generally in Figure 2, SWAT subsequently simulates the behavior of the watershed in response to these land use decisions. The GA then evaluates the fitness of current land use patterns and specifies new patterns, based on the feedback obtained from the simulation model. This feedback loop is repeated until specified convergence criteria are obtained. A detailed schematic of the integrated model developed is provided in Figure 3.

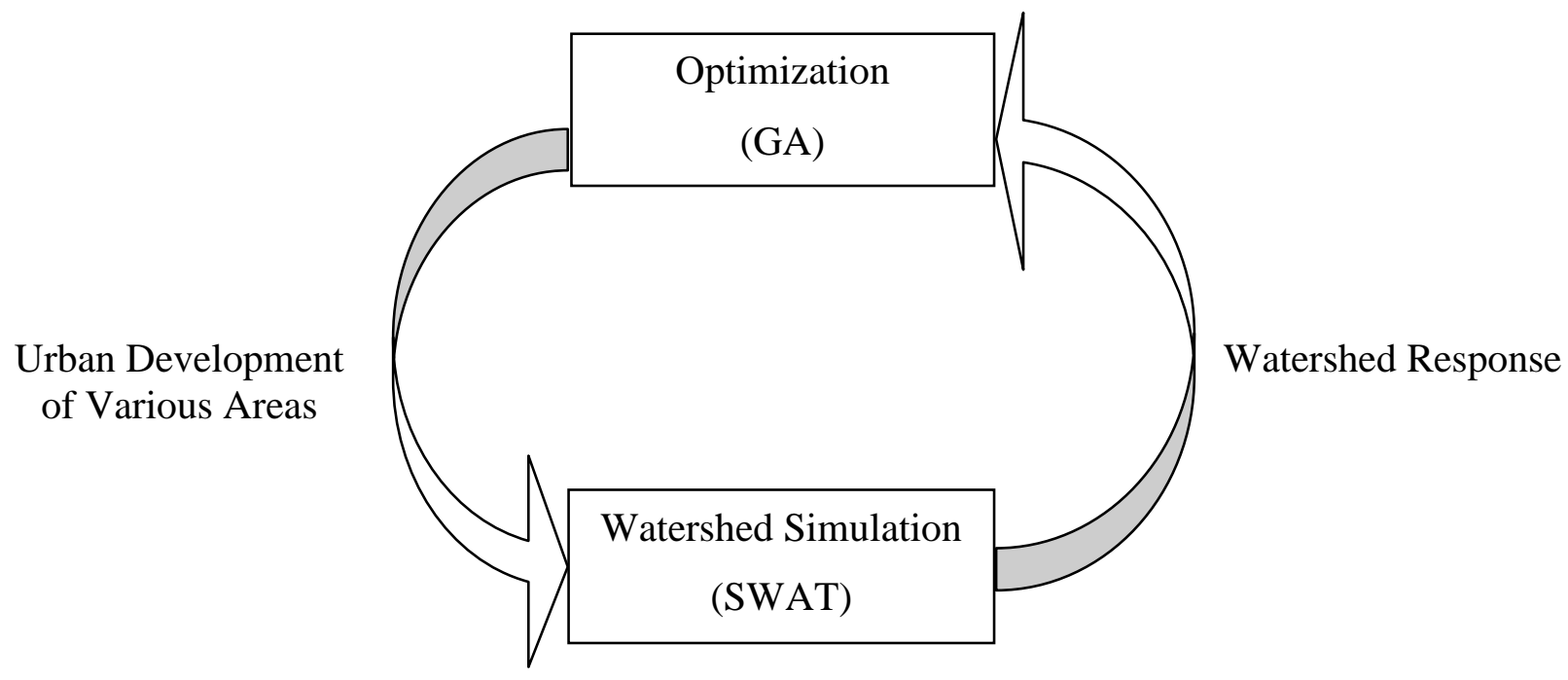

Figure 2. Optimal Control Solution Framework 


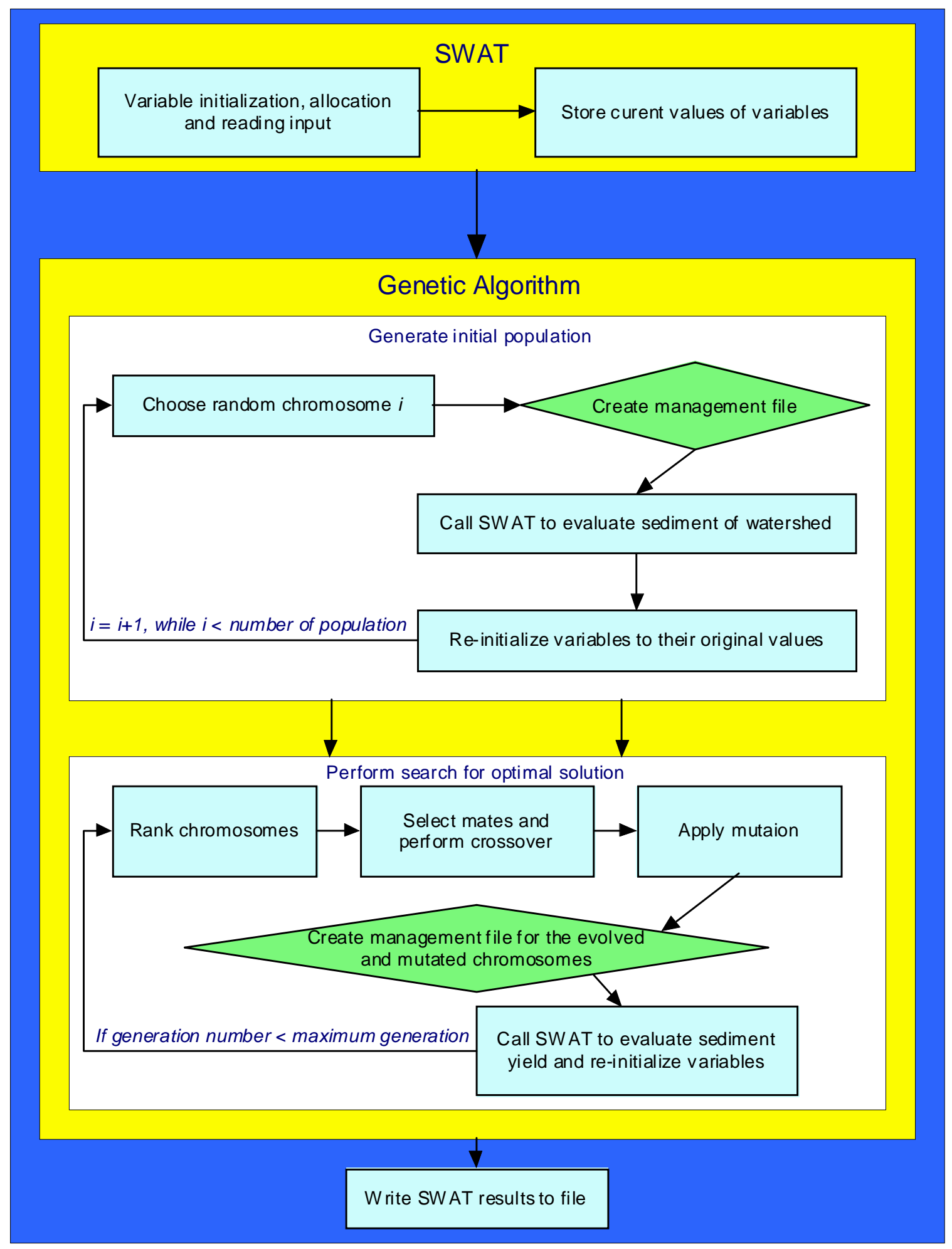

Figure 3. Schematic of GA/SWAT Integration 
The fitness of a particular solution with respect to the overall model objectives is defined by a single aggregate function. Specifically, the function is a weighted sum of the environmental and economic objectives. In this initial application, only the control of sediment yield is considered as an environmental objective. Likewise, economic profit is evaluated as a second aggregate function based on proximity of the centroid of each sub-basin to St. Louis, the economic center of the region, and the distance from each centroid to the nearest interstate. The concept implies that urban development of those subbasins that are closer to St. Louis and major interstates connected to St. Louis will incur a larger profit than those that are not.

In execution of the SDSS, the GA generates an initial population of possible solutions, indicating which subbasins should be urbanized with respect to their current land use. The theory is to have a certain percentage of the entire watershed urbanized. For example, consider a watershed with 75 subbasins and 20 percent of the watershed is to be urbanized; then ultimately 15 subbasins will be urbanized. In addition, constraints on feasible land development were imposed. For example, subbasins dominated by forest or wetlands were not considered for urbanization. SWAT simulates the watershed sediment yield that results from each of the specified solutions, upon which a portion of the fitness value is based. A secondary module within ArcView is used to evaluate the economic objective function value, and the GA then assigns a total aggregate fitness value to each solution. The GA operators are subsequently used to rank chromosomes according to fitness of the chromosomes, select the most fit chromosomes, and perform crossover and mutation processes. The result is a new population of solutions, for which the process is repeated. The convergence, or stopping, criterion utilized in this study is a userspecified maximum number of iterations. At termination of a model execution, the fittest solution is taken as the optimal land management decision to be implemented. For different levels of urbanization, Figure 4 illustrates optimal results as evaluated by the model for the Lower Kaskaskia watershed. Subbasins shaded yellow are those designated by the model for urbanization. It should be noted that these results are only used to test the operation of the SDSS, as calibration of SWAT for the study watershed has not been performed to date.

\section{Summary and Future Work}

The results of the historical population survey are somewhat mixed when compared to that which was expected. A general increase in population, particularly for some areas that serve as bedroom communities to St. Louis, was observed. However, some census tracts showed a decrease in overall population when an increase in population was expected. Overall, however, the survey indicates that the Lower Kaskaskia watershed had been subjected to some degree of urbanization. Corresponding historical flow and sediment data, too extensive too include here, indicate that this urbanization likely impacted on runoff quantity and sediment loads.

The results of the initial application demonstrate the capability of the SDSS to identify optimal land use patterns that limit sediment yield, while promoting profit to be earned from urbanization. These results, and those from earlier test runs, have been presented at meetings with planners and stakeholders of the Lower Kaskaskia watershed. These individuals were identified based on a historical review of watershed planning activities and stakeholder groups. 
The meetings have allowed direct dissemination of the research to affected groups and have allowed for the intermediate integration of feedback from potential users. For example, constraints to disallow development of forest or wetland areas, as well as the integration of distance to interstates within the economic-related objective function were concepts suggested in those meetings.

Future work will focus on calibration of SWAT for the Lower Kaskaskia watershed; development of a second search mechanism, an artificial life algorithm, to verify optimal results specified by the GA; and expansion of the environmental objective to include other water quantity/quality factors (i.e., peak flow, nitrogen concentrations, and phosphorus loads).

$10 \%$ Urbanized

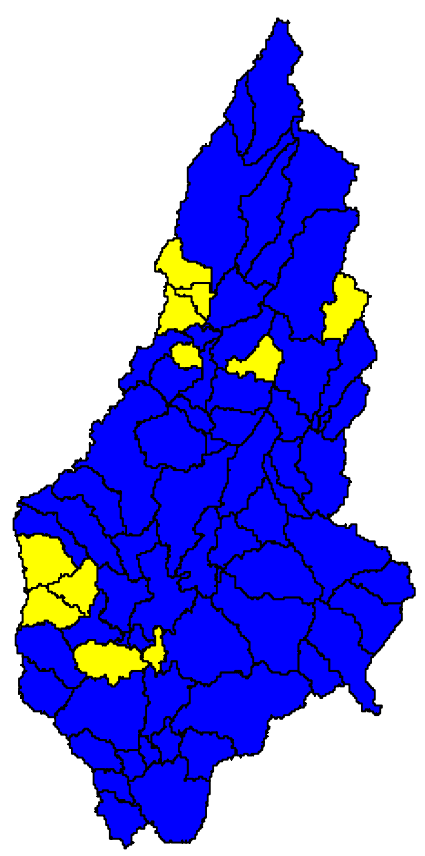

$15 \%$ Urbanized

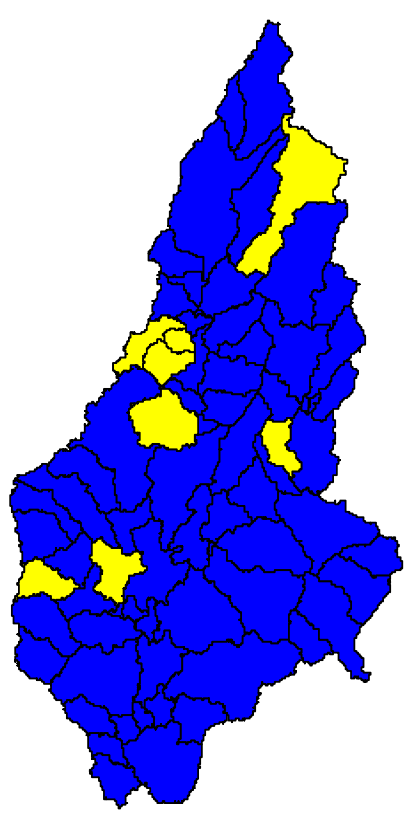

WEIGHTING

$70 \%$ Sediment $\quad 30 \%$ Profit (Distance)

Figure 4. Optimal Development of Urban Subbasins 


\section{References}

Arnold, J.G., Srinivasan, R., Muttiah, R.S., and Williams, J.R. (1998). "Large area hydrologic modeling and assessment Part I: Model development." J. American Water Resources Assoc., 34(1): 73-89.

Carver, S.J. (1991). "Integrating multi-criteria evaluation with geographical information systems.” Int. J. Geographic Information Systems, 5(3): 321-339.

Dangermond, J. (1987). "The maturing of GIS and a new age for geographic information modeling (GIMS)." Proceedings of the International Geographic Information System Symposium: The Research Agenda, Vol. II, NASA, Washington, DC.

DeMers, M.N. (2000). Fundamentals of Geographic Information Systems. Wiley, New York.

Densham, P.J. (1991). "Spatial decision support systems.” In Geographical Information Systems: Principles and Applications. D.J. Macquire, M.F. Goodchild, and D.W. Rhind (Eds.), Longman, Harlow, Essex.

Haupt, R.L. and Haupt, S.E. (1998). Practical Genetic Algorithms. Wiley, New York.

IWMC (2003). "Modified universal soil-loss equation.” Illinois Watershed Management Clearinghouse, <http://web.aces.uiuc.edu/watershed/model/Musle.htm> (January 22, 2003).

Jankowski, P. (1995). "Integrating geographical information systems and multiple criteria decision-making methods.” Int. J. Geographic Information Systems, 9(3): 251-273.

Nyerges, T.L., (1993). "Understanding the scope of GIS: Its relationship to environmental modeling." In Environmental Modeling with GIS. M.F. Goodchild, B.O. Parks, and L.T. Steyaert (Eds.), Oxford University Press, New York.

Sprague, R.H. (1980). "A framework for the development of decision support systems." Management Information Sciences Quarterly, 4(1), 1-26.

USCB (2000). “Census tracts and block numbering areas.” United States Census Bureau, Geography Division, <http://www.census.gov/geo/www/cen_tract.html> (April 5, 2002).

USDA (2000). "Soil and water assessment tool." United States Department of Agriculture Research Service. <http://www.brc.tamus.edu/swat/> (January 21, 2003).

Voogd, H. (1983). Multicriteria Evaluation for Urban and Regional Planning. Pion, London.

\section{Acknowledgements}

The authors would like to thank the Illinois Water Resources Center and Southern Illinois University at Carbondale for their gracious support of this ongoing research effort. 